\title{
LA PROBLEMÁTICA DEL ORIGEN DE LOS IBEROS SEGÚN LA SECUENCIA GENÉTICA DE LOS RESTOS HUMANOS
}

\author{
EDUARDO ARROYO PARDO \\ EVA FERNÁNDEZ DOMÍNGUEZ \\ Dpto. Toxicología y Legislación Sanitaria. \\ Universidad Complutense. Madrid \\ ARTURO OLIVER FOIX \\ Museo de BB.AA. Castellón
}

\begin{abstract}
Resumen. La presencia de restos humanos de personas adultas en el yacimiento ibérico del Puig de la Nau de Benicarló, ha permitido la identificación del ADNmt correspondiente, a través del cual se ha constatado la pertenencia de los individuos analizados al haplogrupo $V$ que se encuentra actualmente en el País Vasco y en Escandinavia.

Palabras clave.ADN antiguo, Antropología Física, Cultura Ibérica
\end{abstract}

\begin{abstract}
The presence of human adult remains in the Puig de la Nau of Benicarló Iberian settlement, has permitted the identification of the corresponding mtDNA, through which it has been established that the analyzed individuals belonged to the haplogroup $\mathrm{V}$, a group also found nowadays in the Basque Country and Scandinavia.

Key words. Ancient mtDNA, Physical anthropology, Iberian Culture
\end{abstract}

El rito de la cremación de los muertos practicada por los iberos, siempre ha sido un problema a la ahora de conocer los caracteres antropológicos de este pueblo mediterráneo de la Antigüedad, pero a pesar de ello, a lo largo de toda la historiografía ibérica el tema siempre se ha abordado con más o menos intensidad desde hace dos siglos. Aunque empíricamente no se ha podido obtener unas características antropológicas de los iberos, ha sido un buen número los autores que han planteado el origen geográfico de los iberos y con ellos sus características antropológicas, teniendo como base en la mayoría de los casos, las diferentes teorías históricas sobre las invasiones, oleadas y desplazamiento de pueblos enteros a lo largo de la Prehistoria, y su consiguientes consecuencias.

Estas teorías invasionistas se basaban en que el cambio de cultura material detectado en los yacimientos arqueológicos, era debido a la suplantación de diferentes grupos humanos por otros procedentes de fuera y que se habían impuesto por su mayor capacidad militar o económica. Unas teorías las podemos reseguir hasta mediados del siglo pasado a través de la bibliografía.
El erudito alemán Alexander von Humboldt ya en 1821, basándose en el interés que se había mostrado en el siglo XVIII por el problema denominado vascoiberismo, consideró que los iberos eran los descendientes de los vascos. Con ciertas matizaciones esta teoría fue defendida por A. Schulten, pues consideraba a los iberos como procedentes de África, y que su perduración se encontraba entre los vascos. La teoría tenía como base la cuestión lingüística planteada en 1804 por L. Hervas Pandero. Cuestión que fue recogida a mediados del siglo $X X$, y después de décadas de olvido, especialmente por autores como R. Menéndez Pidal, P. Beltrán Villagrasa, A. Tovar, J. Caro Baroja y D. Fletcher.

Otras teorías sobre el origen étnico de los iberos, situaban su punto de partida en el ámbito atlántico y americano, como es el caso de L. d'Abartiague y Parmentir. La procedencia asiática, ya sea anatólica o mesopotámica, era una hipótesis que se desarrolló a finales del siglo XIX y principio del XX. Una propuesta más cercana es la de E. Phillipon quien les da un origen ligur.

Estas propuestas se quedan en la mera anécdota historiográfica, siendo la de P. Lemiere, realizada en 1881 , quien defiende un origen 
centroeuropeo, es decir relacionó a los iberos con los celtas, la que tuvo un mayor eco, ya que fue defendida con ciertos vaivenes en su trayectoria investigadora, por J. Martínez Santa-Olalla y Martín Almagro Basch. Propuestas de oleadas centroeuropeas en periodos preibéricos que en cierta medida definirían el sustrato indígena entre los pueblos ibéricos del nordeste. Esta tesis era propia del entorno social y político del momento, en el que se buscaba un acercamiento cultural y política con los países centroeuropeos.

Más aceptación tuvo la propuesta africanista de P. Bosch Gimpera quien proponía un mestizaje entre capsienses y pirinaicos, con celtas y pueblos mediterráneos. Un proceso que tuvo origen durante el Neolítico. En ella se basaron los estudios del ya mencionado A. Schulten y de L. Pericot, este último llegando a considerar un primer origen en Egipto. También se encuentran la propuesta en algunos trabajos de J. Martínez Santa-Olalla, J. San Valero y R. Menéndez Pidal. Todavía podemos recordar los mapas de los antiguos libros de bachillerato en los que se indicaba la procedencia de los celtas peninsulares provenientes del centro de Europa indicando su color de pelo rubio y su mayor altura en relación a los iberos, que además eran morenos, ya que provenían, como indicaba la flecha del mapa, de África.

Las medidas craneales de los enterramientos prehistóricos, y las tradiciones de la cultura material, así como las lingüísticas, eran la base de estas diferentes y variadas teorías. Unas teorías que venían apoyadas también por los planteamientos difusionistas y emigratorios de V. G. Childe, arqueólogo que gozaba de gran predicamento en esa época.

Actualmente se considera el origen ibero como un proceso de cambio cultural debido al propio desarrollo interno del sustrato indígena, sobre el que actúan una serie de influencias procedentes de otros pueblos, que según la zona pueden ser meramente mediterráneas o también centroeuropeas. Este planteamiento lo realizó D. Fletcher, en la década de los cincuenta, quien considera que no hubo ni eliminación ni suplantación alguna, siendo una misma constante mediterránea la que desde la prehistoria se mantiene en las tierras en donde se desarrolla la Cultura Ibérica. Así pues, superadas las teorías de cambios radicales de población, nos encontramos que el Mundo lbérico surge de un proceso cultural y económico que se da especialmente entre el siglo VII y VI a.C., momento en que la cultura material que nos aportan los yacimientos empieza a cambiar, para a mediados del VI a.C. encontrarnos con una cultura prácticamente formada, en donde las "ciudades estado" serían la base social y organizativa de los grupos humanos, quedando conceptos como el de "pueblo" "gens" o "tribu" de los que nos hablan las fuentes escritas, es el caso de los edetanos, turdetanos, cessetanos, etc., sin saber su definición exacta y su relación entre ellos.

Durante las últimas décadas del siglo $X X$ las premisas del materialismo histórico y de la arqueología procesual que se encuentran en boga entre los arqueólogos españoles, alimentan aún más las teorías sobre el autoctonismo y el desarrollo lineal de las diferentes culturas de un espacio geográfico determinado, alejando así los planteamientos que tenían como base la emigración de grandes o pequeños grupos humanos.

No obstante, últimamente dentro de la arqueología y la antropología se vuelven a plantear teorías que aceptan desplazamientos de grupos humanos como factor determinante para los cambios culturales, pero en este caso los desplazamientos son a una escala diferente a la que se había planteado hasta entonces. La propuesta ha sido retomada de vez en cuando por algunos investigadores de la Cultura Ibérica, así F. Burillo y I. Aguilera y I. Royo plantearon una aportación de población transpirenaica en la zona del valle medio del río Ebro (Aguilera, Royo, 1978; Burillo, 1980 ) y desde otras zonas más iberizadas (BuriIlo, 1980), no obstante, F. Burillo en trabajos posteriores rechaza la hipótesis invasionista (Burillo, 1989-90), al igual que también rechaza que algunos cambios sociales y culturales se produzcan por el desplazamiento de grupos humanos desde la costa al interior del valle del Ebro (Burillo, 2001-2002). Este desplazamiento de grupos de gente de la costa hacia el interior, como justificación de una serie de cambios localizados a través de la arqueología, también ha sido apoyado por otros investigadores (Arteaga et al., 1990; Tramillas, Alfranca, 1995).

Recientemente se vuelve a apuntar desplazamientos humanos, en este caso desde el sudeste al nordeste, para justificar la rápida aparición de la Cultura Ibérica en Cataluña (Sanmartí, Santacana, 2005).

Estas propuestas de emigraciones desde zonas cercanas aunque fueran ciertas, seguramente no afectarían a cambios antropológicos en la zona de recepción de los emigrantes.

Los nuevos planteamientos a la hora de hablar de las características antropológicas de los iberos, pueden cambiar debido a que existen nuevas teorías a partir de bases empíricas más seguras, dejando de ser este tipo de propuestas 


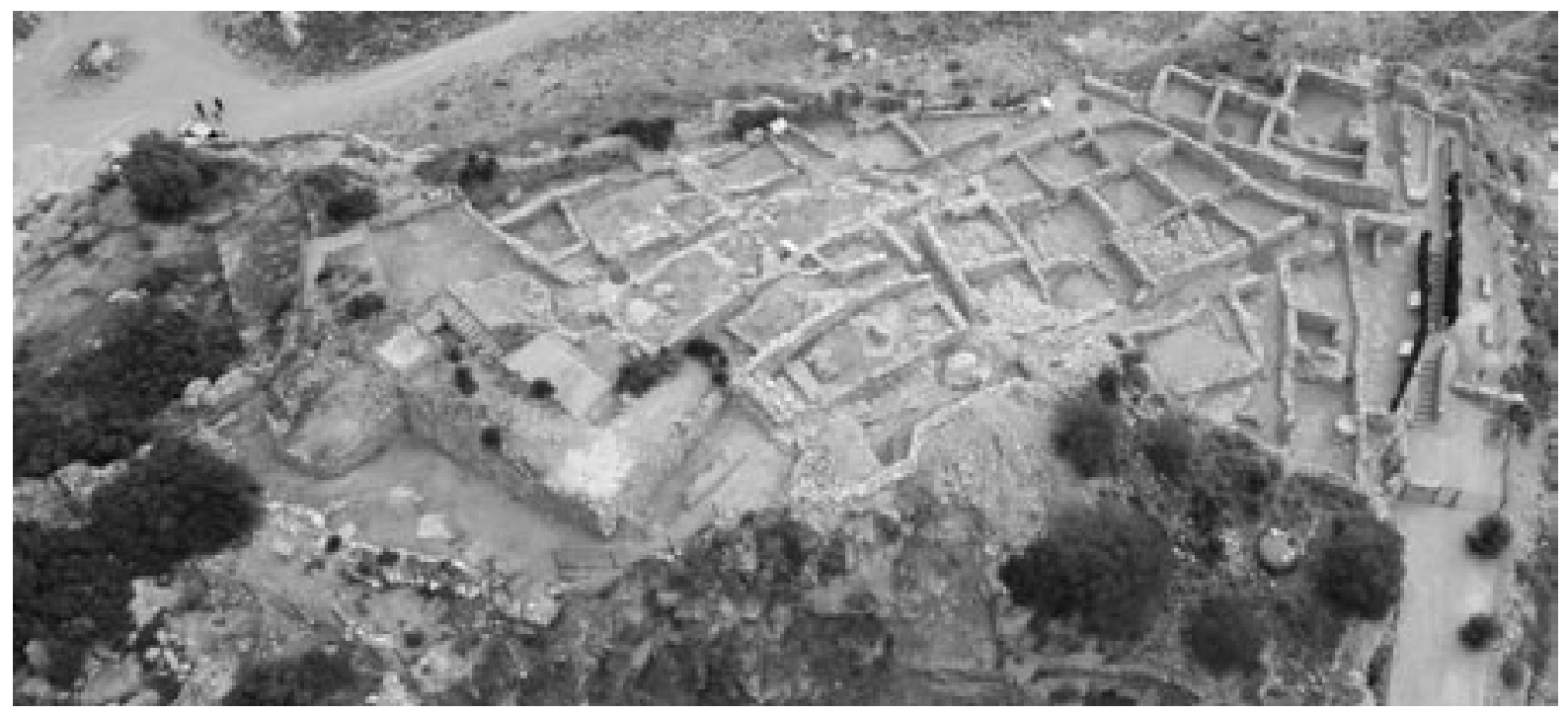

Figura 1: Vista del asentamiento del Puig de la Nau indicando los lugares en donde se han localizado restos humanos de personas adultas.

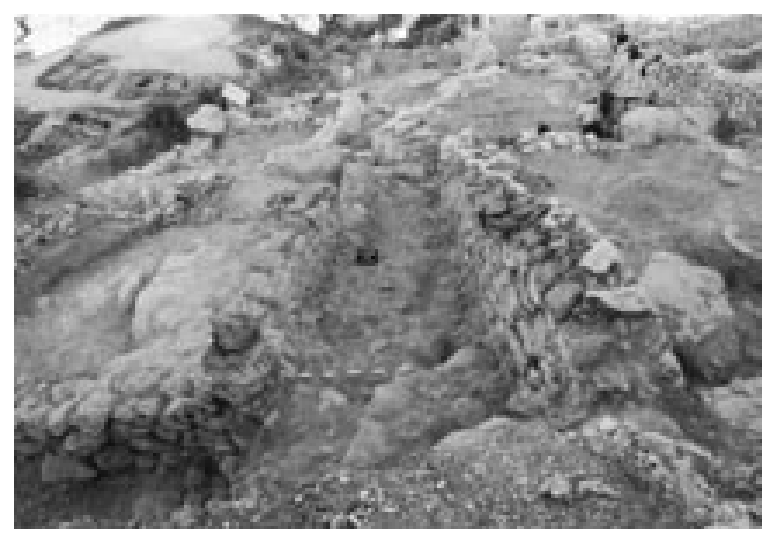

Figura 2: Calle H del Puig de la Nau en cuyo nivel de derrumbe había restos humanos de personas adultas

meras elucubraciones. Las metodologías biológicas recientemente incorporadas a la arqueología, han podido aprovechar los pequeños fragmentos óseos localizados en las urnas de cremación para al menos, conocer edades, sexo y patologías, aunque en gran parte de las muestras resultan infructuosos los análisis metrológicos y/o oculares. No obstante, las técnicas de la antropología forense que a partir de los años ochenta se han aplicado a las cremaciones por investigadores especializados en el tema, han dado estupendos resultados para el conocimiento antropológico de los iberos (Gómez, 1996; Miguel, 200).

Actualmente se está iniciando una nueva etapa metodológica con la aplicación de los análisis genéticos para obtener el ADN de los restos óseos procedentes de los yacimientos ibéricos. Con esta nueva técnica podremos definir secuencias que nos indiquen el haplotipo al que pertenece el individuo analizado, así como obtener otros

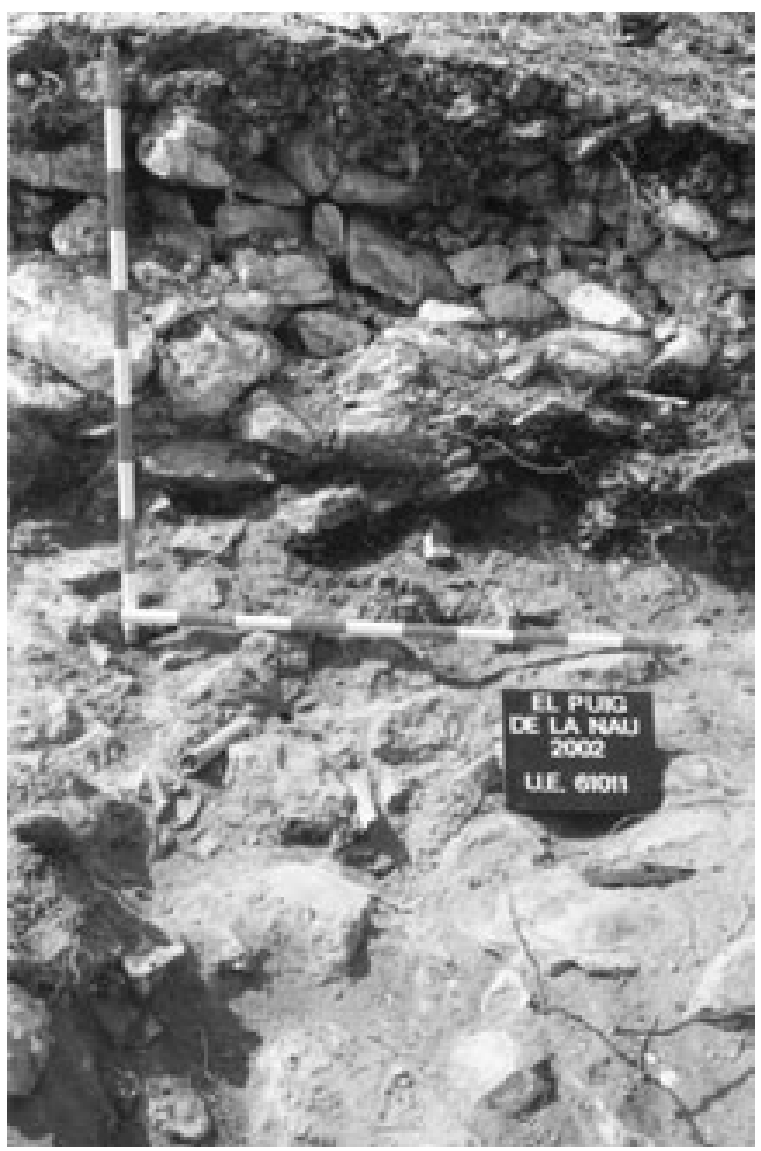

Figura 3: Detalle del hallazgo de los restos humanos en la calle $\mathrm{H}$ del Puig de la Nau.

resultados que completen el estudio antropológico, como es el caso del sexo, relaciones familiares, relación entre diferentes grupos humanos y procedencia geográfica, así como la actual situación del haplotipo detectado en las muestras. 
Indudablemente nos volvemos a encontrar con la problemática de la cremación, ya que ésta destruye la secuencia de ADN, y no permite obtener ningún tipo de resultado. Sin embargo, aunque no es frecuente, en las diferentes memorias arqueológicas que se publican, vemos como poco a poco van apareciendo algunos restos humanos en los propios lugares de hábitat ibéricos (Oliver, 1995; 2006). Estos restos, normalmente fragmentos de cráneo o de las extremidades, presentan una problemática social y ritual de la que no vamos a tratar aquí, ya que de ellos nos interesa de momento, la posibilidad de obtener muestras para la obtención de las secuencias del ADN correspondiente. Hasta el día de hoy, estos estudios se han realizado en los restos procedentes de los yacimientos gerundenses de Mas Castellar en Pontós, Puig de Sant Andreu y l'llla d'en Reixach ambos en Ullastret (Sampietro, Caramelli, et al., 2005), y en el yacimiento del Puig de la Nau de Benicarló, los cuales presentamos en este estudio (Figura 1-3).

\section{METODOLOGÍA EMPLEADA}

\section{Limpieza y trituración de las muestras}

Las muestras se limpiaron en superficie mediante óxido de aluminio a presión con una "arenadora" Sand-blaster Dentalfarm, modelo Base 1 Plus, con el fin de eliminar la capa más externa, y con ella parte de la suciedad procedente del enterramiento y posibles moléculas de ADN contaminante.

Una vez realizada la limpieza, se irradiaron con luz ultravioleta (UV) durante 30 minutos en el interior de una campana de flujo laminar.

Las muestras limpias fueron trituradas en un molino refrigerado con nitrógeno líquido.

\begin{tabular}{|c|c|c|c|c|c|c|}
\hline $\begin{array}{c}\text { Código } \\
\text { laboratorio }\end{array}$ & Yacimiento & $\begin{array}{c}\text { Referencia } \\
\text { arqueológica }\end{array}$ & $\begin{array}{l}\text { Tipo de } \\
\text { muestra }\end{array}$ & Observaciones & $\begin{array}{c}\text { Sexo } \\
\text { antropológico }\end{array}$ & $\begin{array}{c}\text { Edad } \\
\text { antropológica }\end{array}$ \\
\hline PB1 & $\begin{array}{l}\text { Puig de la Nau } \\
\text { (Benicarló) }\end{array}$ & Recinto 3. N. IV & Íleon & & & Neonato \\
\hline PB2 & $\begin{array}{l}\text { Puig de la Nau } \\
\text { (Benicarló) }\end{array}$ & Recinto 5. N. V & Tibia dcha. & & & Neonato \\
\hline PB3 & $\begin{array}{l}\text { Puig de la Nau } \\
\text { (Benicarló) }\end{array}$ & U.E. 64040 & Cúbito izq. & & & Neonato \\
\hline PB4 & $\begin{array}{l}\text { Puig de la Nau } \\
\text { (Benicarló) }\end{array}$ & U.E. 38030 & Cúbito dcho. & & & Neonato \\
\hline PB5 & $\begin{array}{c}\text { Puig de la Nau } \\
\text { (Benicarló) }\end{array}$ & U.E. 38028 & Radio dcho. & & & Neonato \\
\hline PB7 & $\begin{array}{l}\text { Puig de la Nau } \\
\text { (Benicarló) }\end{array}$ & U.E. 1045-1044 & Cúbito dcho. & & & Neonato \\
\hline PB8 & $\begin{array}{c}\text { Puig de la Nau } \\
\text { (Benicarló) }\end{array}$ & U.E. 1030 & Cúbito izq. & & & Neonato \\
\hline PB9 & $\begin{array}{l}\text { Puig de la Nau } \\
\text { (Benicarló) }\end{array}$ & $\begin{array}{c}\text { Esqueleto } \\
61012\end{array}$ & Diáfisis fémur & Muy deteriorado & $\begin{array}{l}\text { Posiblemente } \\
\text { femenino }\end{array}$ & Adulto \\
\hline PB10 & $\begin{array}{l}\text { Puig de la Nau } \\
\text { (Benicarló) }\end{array}$ & $\begin{array}{c}\text { Esqueleto } \\
61012\end{array}$ & Diáfisis fémur & Muy deteriorado & $\begin{array}{l}\text { Posiblemente } \\
\text { femenino }\end{array}$ & Adulto \\
\hline PB11 & $\begin{array}{l}\text { Puig de la Nau } \\
\text { (Benicarló) }\end{array}$ & $\begin{array}{c}\text { Esqueleto } \\
61012\end{array}$ & Diáfisis fémur & & Masculino & Maduro-senil \\
\hline PB12 & $\begin{array}{l}\text { Puig de la Nau } \\
\text { (Benicarló) }\end{array}$ & $\begin{array}{c}\text { Esqueleto } \\
61012\end{array}$ & Diáfisis fémur & & Masculino & Maduro-senil \\
\hline PB13 & $\begin{array}{l}\text { Puig de la Nau } \\
\text { (Benicarló) }\end{array}$ & $\begin{array}{c}\text { Esqueleto } \\
61012\end{array}$ & Fémur & & Masculino & Senil \\
\hline PB14 & $\begin{array}{l}\text { Puig de la Nau } \\
\text { (Benicarló) }\end{array}$ & $\begin{array}{c}\text { Esqueleto } \\
61012\end{array}$ & Fémur & & Masculino & Senil \\
\hline PB15 & $\begin{array}{l}\text { Puig de la Nau } \\
\text { (Benicarló) }\end{array}$ & $\begin{array}{c}\text { Esqueleto } \\
61012\end{array}$ & Diáfisis fémur & & ? & Adulto \\
\hline PB16 & $\begin{array}{l}\text { Puig de la Nau } \\
\text { (Benicarló) }\end{array}$ & $\begin{array}{c}\text { Recinto 1. Nivel } \\
\text { II. Calle A }\end{array}$ & Diáfisis húmero & Muy deteriorado & & Adulto \\
\hline PB17 & $\begin{array}{c}\text { Puig de la Nau } \\
\text { (Benicarló) }\end{array}$ & $\begin{array}{l}\text { Recinto 4. Calle } \\
\text { B. Nivel II. }\end{array}$ & Diente & Raíz rota & & Adulto \\
\hline PB18 & $\begin{array}{l}\text { Puig de la Nau } \\
\text { (Benicarló) }\end{array}$ & $\begin{array}{l}\text { Recinto 4. Calle } \\
\text { B. Nivel II. }\end{array}$ & Metatarsiano? & & & Adulto \\
\hline
\end{tabular}

Figura 4: Tabla 1. 


\section{Extracción del material genético}

El polvo de hueso resultante de la trituración fue lavado varias veces con EDTA $0.5 \mathrm{M}$ para eliminar el calcio y posteriormente incubado toda la noche en solución de lisis con proteinasa $K$, para digerir las proteínas y liberar el ADN.

La extracción del ADN total se realizó mediante un protocolo estándar Fenol/Cloroformo y se concentró con microconcentradores Centriplus-30000.

\section{Detección de inhibidores de la reacción de amplificación}

Se realizó una prueba sencilla para detectar la presencia de moléculas inhibidoras de la $P C R$, generalmente procedentes del entorno del enterramiento o de la propia degradación del resto, y evaluar, por tanto, las posibilidades de éxito de los análisis posteriores.

Para ello se prepararon reacciones de PCR de $25 \mu$ de volumen final con 100 ng de ADN fresco a las que se añadieron tres volúmenes diferentes de cada uno de los extractos de ADN antiguo $(5 \mu \mathrm{l}, 2.5 \mu \mathrm{l}$ y $1 \mu \mathrm{l})$. El conjunto se amplificó con cebadores específicos de la región hipervariable I (HVRI) del ADN mitocondrial. Los resultados se visualizaron en geles de agarosa al $2 \%$, interpretándose la ausencia o disminución de la banda de amplificación como signo de la presencia de inhibición para dicha cantidad y dicho extracto de ADN antiguo.

\section{Cuantificación de ADN}

Previamente a su amplificación, y de la misma manera que sucede con el ensayo de inhibición, resulta de gran interés para determinar las probabilidades de éxito en la obtención de información genética de un determinado conjunto de muestras, realizar una cuantificación específica del material genético que se desea amplificar. El material genético extraído de restos antiguos, además de ser escaso, está muy fragmentado, lo que hace imposible en la mayor parte de los casos la recuperación de fragmentos de ADN de tamaño superior a 300 pares de bases.

Se estimó la cantidad total de ADN extraído mediante espectrofotometría, empleando un "Nanodrop".

\section{Amplificación del ADN mitocondrial}

La región objeto de estudio corresponde a un fragmento de 244 pares de bases editadas de la Región Hipervariable I (HVSI) del ADN mitocondrial (posiciones 16126-16369). Esta región fue seleccionada y copiada en dos amplificaciones solapantes mediante la Reacción en cadena de la polimerasa (PCR) usando cebadores específicos que proporcionaban dos productos de amplificación de 133 y 112 pares de bases.

Los productos de amplificación se secuenciaron en un secuenciador automático (ABIPRISM 3700). Las secuencias así obtenidas se compararon con la secuencia consenso de Cambridge (CRS) (Anderson et al., 1981), la más común entre la población Europea.

\section{Determinación molecular del sexo}

La determinación molecular del sexo de las muestras se realizó a través del estudio de una región del gen de la amelogenina, presente en los dos cromosomas sexuales $X$ e $Y$, pero no $100 \%$ homóloga (Sullivan et al., 1993).

\begin{tabular}{|c|c|c|c|c|c|c|}
\hline $\begin{array}{c}\text { Código } \\
\text { laboratorio }\end{array}$ & Yacimiento & $\begin{array}{c}\text { Referencia } \\
\text { arqueológica }\end{array}$ & $\begin{array}{l}\text { Tipo de } \\
\text { muestra }\end{array}$ & Observaciones & $\begin{array}{c}\text { Sexo } \\
\text { antropológico }\end{array}$ & $\begin{array}{c}\text { Edad } \\
\text { antropológica }\end{array}$ \\
\hline PB19 & $\begin{array}{c}\text { Puig de la Nau } \\
\text { (Benicarló) }\end{array}$ & Recinto 9 & $\begin{array}{c}\text { Diáfisis } \\
\text { humero } \\
\text { dcho. }\end{array}$ & & & Adulto \\
\hline PB20 & $\begin{array}{l}\text { Puig de la Nau } \\
\text { (Benicarló) }\end{array}$ & $\begin{array}{l}\text { Recinto 11. Nivel } \\
\text { II. Calle B }\end{array}$ & $\begin{array}{c}\text { Diáfisis tibia } \\
\text { dcha. }\end{array}$ & & Masculino? & Adulto \\
\hline PB21 & $\begin{array}{l}\text { Puig de la Nau } \\
\text { (Benicarló) }\end{array}$ & $\begin{array}{l}\text { Recinto 17. Calle } \\
\text { C. Nivel II. }\end{array}$ & Diente & & & Adulto \\
\hline PB22 & $\begin{array}{c}\text { Puig de la Nau } \\
\text { (Benicarló) }\end{array}$ & $\begin{array}{l}\text { Recinto 17. Calle } \\
\text { C. Nivel I. }\end{array}$ & Diente & & & Adulto \\
\hline PB23 & $\begin{array}{c}\text { Puig de la Nau } \\
\text { (Benicarló) }\end{array}$ & Callejón & Húmero & & & Adulto \\
\hline
\end{tabular}

Figura 5: Tabla 2. 


\begin{tabular}{|c|c|c|c|c|c|c|c|c|c|c|}
\hline \multirow[t]{3}{*}{$\begin{array}{c}\text { Código } \\
\text { laboratorio }\end{array}$} & \multicolumn{3}{|c|}{$\begin{array}{l}\text { Inhibición a } \\
\text { cantidades }\end{array}$} & \multirow[t]{3}{*}{ Cuantificación } & \multicolumn{2}{|c|}{ Diagnóstico de sexo } & \multicolumn{4}{|c|}{ ADN mitocondrial } \\
\hline & \multirow[t]{2}{*}{$5 \mu \mathrm{l}$} & \multirow[t]{2}{*}{$2.5 \mu \mathrm{l}$} & \multirow[t]{2}{*}{$1 \mu \mathrm{I}$} & & \multirow{2}{*}{\begin{tabular}{|c|}
$\mathbf{N}^{\circ}$ \\
ensayos
\end{tabular}} & \multirow[t]{2}{*}{ Resultado } & \multicolumn{2}{|c|}{$\mathrm{N}^{\circ}$ ensayos } & \multicolumn{2}{|c|}{ Resultado } \\
\hline & & & & & & & \begin{tabular}{|c|}
1 er \\
fragmento
\end{tabular} & $\begin{array}{c}2^{\circ} \\
\text { fragmento }\end{array}$ & \begin{tabular}{|c|}
$1 \mathrm{er}$ \\
fragmento
\end{tabular} & $2^{\circ}$ fragmento \\
\hline PB1 & + & + & + & 144,73 & 4 & & & & & \\
\hline PB2 & + & + & - & 99,44 & 2 & & & & & \\
\hline PB3 & + & + & - & 95,78 & 6 & & & & & \\
\hline PB4 & + & + & + & 101,25 & 4 & & & & & \\
\hline PB5 & + & - & - & 43,59 & 6 & & & & & \\
\hline PB7 & + & + & - & 76,77 & 4 & & & & & \\
\hline PB8 & + & + & - & 108,05 & 6 & & & & & \\
\hline PB9 & + & + & - & 89,02 & & & 2 & 1 & - & - \\
\hline PB10 & + & - & - & 88,15 & & & 2 & 1 & - & - \\
\hline PB11 & + & + & - & 51,27 & & & 1 & 1 & - & - \\
\hline PB12 & + & - & - & 49,03 & & & 1 & 1 & - & - \\
\hline PB13 & - & - & - & 61,59 & & & 4 & 3 & - & - \\
\hline PB14 & - & - & - & 144,27 & & & 4 & 2 & - & 16293T,16298C \\
\hline PB15 & + & - & - & 42,52 & & & 1 & 1 & - & - \\
\hline \multicolumn{11}{|l|}{ PB16 } \\
\hline \multicolumn{11}{|l|}{ PB17 } \\
\hline PB18 & + & - & - & 76,89 & & & & & & \\
\hline PB19 & + & - & - & 73,37 & & & & & & \\
\hline PB20 & - & - & - & 23,2 & & & 3 & 1 & - & 16293T,16298C \\
\hline \multicolumn{11}{|l|}{ PB21 } \\
\hline \multicolumn{11}{|l|}{ PB22 } \\
\hline PB23 & & & & & & & 1 & 6 & CRS & - \\
\hline
\end{tabular}

Figura 6: Tabla 3.

Mediante una amplificación con cebadores específicos y una posterior visualización en un analizador de fragmentos (ALF-Pharmacia), pueden distinguirse a simple vista los individuos masculinos de los femeninos, puesto que los primeros presentarán dos picos y los segundos únicamente uno.

\section{RESULTADOS}

En la Tabla 2 se resumen el tipo de pruebas realizadas sobre cada muestra y los resultados obtenidos.

\section{Detección de inhibidores de la reacción de amplificación}

De las 17 muestras de Puig de la Nau en las que fue evaluada la presencia de inhibidores de la PCR en los extractos de ADN, 14 presentaban en los extractos algún tipo de poder inhibidor. Esto supone un porcentaje de muestras con inhibidores del $82.35 \%$.

\section{Determinación molecular del sexo}

Se intentó asignar el sexo a 8 individuos neonatos (PB1-PB8). Para ello, se llevaron a cabo una media de 4.5 ensayos por muestra. En ninguno de los casos se consiguió una amplificación positiva del gen de la amelogenina.

\section{Amplificación del ADN mitocondrial}

Se intentaron amplificar dos segmentos de la región hipervariable I del ADN mitocondrial en 9 individuos adultos. Para ello, se llevaron a cabo una media de 2 ensayos por muestra para cada uno de los dos fragmentos.

Pudieron recuperarse secuencias parciales del primer segmento en un individuo (PB23) $\mathrm{y}$ del segundo segmento en otros dos individuos diferentes (PB14 y PB15).

La secuencia del primer fragmento (posiciones 16126-16256) del individuo PB23 es idéntica a la secuencia consenso. Su frecuencia en poblaciones actuales, según nuestra base de datos (Fernández, 2005) es de 27.49\%. 
Las dos secuencias del segundo fragmento (posiciones 16256-16369) de los individuos PB14 y PB15 son iguales entre sí y presentan dos posiciones mutadas respecto a la secuencia consenso. Esta secuencia no aparece representada en nuestra base de datos de secuencias de poblaciones actuales, ni en otras bases de datos consultadas (mtDNA Population database (Federal Bureau of Investigations, USA); mtDB-Human Mitochondrial Genome Database; Mitochondrial ADN Concordance).

De acuerdo con la mutación 16298C, estas dos secuencias pertenecen al haplogrupo V. Un haplogrupo se define como un grupo de secuencias que comparten determinadas mutaciones y que derivan de una secuencia ancestral común. Estos haplogrupos se designan por letras mayúsculas ( $A, B, C$, etc.), y presentan una distribución específica en cada continente. Los principales haplogrupos Europeos son: $\mathrm{H}$, preHV, HV, I, J, K, T, U1, U2, U3, U4, U5, V (Richards, et al., 2000).

\section{DISCUSIÓN Y CONCLUSIONES}

\section{Preservación del ADN en las muestras analizadas}

El fracaso en la obtención de marcadores nucleares (gen de la amelogenina y cromosoma Y) y la reducida eficiencia de amplificación del ADN mitocondrial se debe, probablemente, a dos factores mutuamente no excluyentes: 1) la presencia de moléculas inhibidoras de la $P C R$ en la mayor parte de los extractos, 2) la deficiente preservación del material genético en los restos analizados.

La presencia de inhibidores ha sido probada mediante la prueba de inhibición en la mayoría de los extractos obtenidos. Los niveles de inhibición encontrados en ellos impiden la amplificación de su ADN por la técnica de $P C R$, paso imprescindible para la obtención de resultados. Este efecto es más significativo en los marcadores nucleares, puesto que el ADN de origen nuclear es entre 1000 y 10000 veces menos abundante que el ADN mitocondrial. Es por ello que, una vez estimado el contenido en inhibidores de los extractos, se centraron los análisis en el estudio del ADN mitocondrial de aquellos sin poder inhibidor.

En cuanto a la preservación del material genético, a priori es imposible saber con certeza si unos restos contienen o no ADN endógeno, sin embargo, el tipo de muestra (hueso, diente, teji- do...) y su estado de preservación externa puede orientar de una forma bastante fiable. Múltiples estudios demuestran que la preservación del material genético en las piezas dentales es mejor que en otros tejidos como el hueso (Kurosaki et al., 1993; Degusta et al., 1994; Woodward et al., 1994; Oota et al., 1995; Zierdt et al., 1996). Las muestras estudiadas en el presente trabajo correspondían, con un par de excepciones, a huesos, generalmente largos. La microestructura de los huesos, carentes de una cubierta protectora como el esmalte dental, favorece la penetración de suciedad del enterramiento. Para el análisis de huesos largos, se requiere además de la obtención de secciones transversales mediante serrado, lo que aumenta la manipulación de los restos y por tanto las probabilidades de contaminación.

\section{Relación de parentesco}

Los resultados obtenidos únicamente permiten inferir relaciones de parentesco a partir de las muestras PB14 y PB15. Aunque también se obtuvo un fragmento de ADN mitocondrial de la muestra PB23, las posiciones analizadas son diferentes, lo que no permite la comparación.

La diferente procedencia y el análisis antropológico garantizan que las muestras PB14 y PB20 proceden de dos individuos diferentes. La coincidencia de sus linajes de ADN mitocondrial únicamente puede explicarse mediante 1) relaciones de parentesco por via materna, 2) azar.

Que se trate de una u otra explicación dependerá de la frecuencia del linaje en cuestión en la población estudiada. Ya que se desconoce la composición genética de las poblaciones iberas, y concretamente, de la población de Puig de la Nau, se utilizó como referencia la población actual de la península Ibérica. La frecuencia de este linaje en la última es igual a 0 . Dado que la composición genética de las poblaciones puede haber cambiado con el tiempo, por procesos de migración o por puro azar, se amplió el rango de búsqueda a varias bases de datos de secuencias de poblaciones mundiales, citadas ya en el apartado anterior. En ninguna de ellas se encontró dicho linaje.

Para calcular la probabilidad de que los individuos PB14 y PB20 estén emparentados podemos asumir, por tanto, que la frecuencia de su haplotipo es $<6.06 \times 10^{-5}$. Esto significa que la probabilidad de que estos dos individuos fueran 
idénticos por azar, suponiendo que la distribución de frecuencias del pasado pueda equipararse a la actual, es menor que $\left(6.06 \times 10^{-5}\right)^{2}$, lo que equivale a menos de $6.06 \times 10^{-10}$. Esta probabilidad es lo suficientemente pequeña como para apoyar la hipótesis de que PB14 y PB20 están relacionados genéticamente por vía materna. En términos probabilísticos, puede decirse que la probabilidad de que dichos sujetos hubieran sido muestreados aleatoriamente de una población donde la frecuencia del haplotipo 16293T16298C fuera menor a $6.06 \times 10^{-5}$, es $6.06 \times 10^{-10}$. Si el problema se planteara a modo de caso forense sería:

\section{$\mathrm{P}$ (identidad de las 2 muestras condicionada a su igualdad por descendencia)}

$\mathrm{P}$ (identidad de las 2 muestras condicionada a su identidad por azar)

Dado que la probabilidad de que dos individuos iguales por descendencia materna compartan el mismo ADN mitocondrial es igual a 1, la relación sería $1 / 6.06 \times 10^{-10}$, que equivale a 1650165016 . Si la probabilidad de parentesco se calcula como,

$$
W=I P \times(1+I P)^{-1}
$$

Entonces 1650165016/1650165017 es igual 0.999999999394 (99.9999999\%). Este valor, en caso de tratarse de una peritación forense, sería superior a 400 o $99.75 \%$-valor umbral que marca la ley, por ejemplo, en pruebas de paternidad-, y en principio sería considerado concluyente.

Este tipo de peritaciones se realizan con marcadores de ADN nuclear autosómicos, heredados del padre y de la madre y con gran poder discriminador. Sin embargo, el ADN mitocondrial es un marcador de linaje, no de individuo, que hace indistinguible a toda la línea materna, de manera que, por ejemplo, los hermanos y los primos maternos de primer grado son indiferenciables. Teniendo esto en cuenta, otros grados de parentesco matrilineal, dejando al margen a los hermanos maternos, podrían ser igualmente considerados.

Cabe también la posibilidad de que la identidad mitocondrial de los grupos de individuos considerados se deba a una elevada frecuencia de las secuencias observadas -superior a la actual- en la población a la que pertenecen. Esto no implicaría una relación de parentesco próximo pero podría implicar un parentesco en un grado muy lejano.

\section{Implicaciones poblacionales de los resultados obtenidos}

La ausencia de los haplotipos de ADN mitocondrial recuperados de los individuos PB14 y PB15 en las bases de datos de poblaciones actuales consultadas sugiere que probablemente se tratara de variantes genéticas abundantes en las poblaciones del pasado, que han desaparecido de las poblaciones actuales por sustitución poblacional o por simple azar. Estas variantes son diferentes a las recuperadas de los yacimientos Calcolíticos de Costa Lloguera en un estudio anterior (Fernández, Arroyo, 2004).

Los haplogrupos a los que pertenecen las muestras de ambos yacimientos son también diferentes. Destaca especialmente la asignación de las muestras de Puig de la Nau al haplogrupo europeo V. La frecuencia y distribución de este haplogrupo en Europa -con máximos en el País Vasco y Escandinavia- ha servido a algunos autores para postular la hipótesis de su origen durante el Paleolítico Superior en la cornisa Cantábrica (Torroni et al., 1998, 2001). Esta región habría servido de refugio a las poblaciones europeas durante el segundo peniglaciar. Tras la retirada de los hielos hace aproximadamente 12000 años se habría producido una recolonización de las poblaciones aisladas en estos refugios Paleolíticos hacia el Noreste (Torroni et al., 1998, 2001). Sin embargo, la elevada frecuencia del haplogrupo $\mathrm{V}$ encontrada actualmente en el País Vasco contrasta con su ausencia en 121 muestras de 4 yacimientos de época Calcolítica-Edad del Bronce de esta misma región (Izaguirre, De la Rúa, 1999). Una disección detallada de los haplotipos y haplogrupos presentes en el grupo Saami ha puesto de manifiesto que los linajes de ADNmt del haplogrupo $\mathrm{V}$ característicos de esta población están mucho más distribuidos en el este que en el oeste de Europa (Tambets et al., 2004; Bermisheva et al., 2002). Este resultado sugiere que el haplogrupo $V$ habría alcanzado Fennoscandia a través de Europa central y del este (Tambets et al., 2004).

La presencia de linajes $V$ en muestras iberas de Castellón, en contraposición con su ausencia en las muestras Calcolíticas estudiadas, podría estar indicando un diferente origen étnico y quizás también geográfico de ambas poblaciones. Esto podría servir para explicar, a su vez, que los individuos iberos recibieran un tratamiento funerario diferente al resto de habitantes del poblado, que eran incinerados, depositados en urnas y enterrados en el suelo de las casas. Este resultado contradice, sin embargo, los resultados de un estudio publicado recientemente en el que se analizaron 
también muestras iberas, en este caso de Cataluña (Sampietro et al., 2005). Ninguna de las muestras estudiadas en dicho trabajo puede atribuirse al haplogrupo $V$, encontrado en las muestras de Puig de la Nau. Todas ellas pertenecen, sin embargo, a los principales haplogrupos Europeos: $\mathrm{H}(52.9 \%), \mathrm{U}(17.6 \%), \mathrm{J}(11.8 \%)$, pre-HV $(5.9 \%), \mathrm{K}$ (5.9\%), T (5.9\%). La conclusión de este estudio es que los antiguos iberos no eran significativamente diferentes de las poblaciones actuales.

Las diferencias entre nuestros resultados y los obtenidos por Sampietro et al., (2005) pueden deberse a diversas causas:

- Gran heterogeneidad genética entre los grupos iberos de Cataluña y los de Castellón.

- Diferente procedencia étnica de los individuos de Puig de la Nau y los de Ullastret.

- A un efecto muestral, pues en nuestro estudio únicamente pudo obtenerse información genética de tres individuos y en el de Sampietro et al., 2005 de 17.

Aún sumando nuestras muestras a las de este último estudio, la frecuencia total del haplogrupo $\mathrm{V}$ en los individuos iberos analizados hasta la fecha sería de un $11.76 \%$, muy superior a la frecuencia media de este haplogrupo en la población actual de la Península (Côrte-Real et al., 1996), y muy similar a la encontrada en los vascos actuales (Torroni et al., 2001).

\section{CONSIDERACIONES FINALES}

A pesar del escaso rendimiento de las muestras estudiadas, los resultados obtenidos ofrecen una perspectiva única, sobre el conocimiento de la composición genética de los pueblos iberos. En este sentido la obtención de una serie de análisis del ADN mitocondrial de muestras de otros yacimientos a lo largo de toda la región ibérica, resultaría altamente recomendable. Los resultados obtenidos en el Puig de la Nau de Benicarló, así como en los yacimientos de la provincia de Gerona, son aún una muestra pequeña para generalizar los resultados obtenidos en ellos. Por otra parte, no podemos perder de vista, que las muestras se obtienen de un registro arqueológico que no es el habitual, huesos humanos en las poblaciones, por lo que se tendría que conocer en primer lugar el significado de la presencia de estos restos en calles y recintos de los diferentes asentamientos, presencia que es la excepción dentro del ritual de enterramiento de cremación practicado por los iberos. La ruptura existente entre las muestras del Puig de la Nau y las prehistóricas de la provincia de Castellón obtenidos en el yacimiento Calcolítico de la Costa Lloguera (Castellón de la Plana), así como con los datos de las muestras actuales, e indudablemente con las muestras de los yacimientos gerundeses, son un ejemplo de la complejidad de la investigación, en donde hay que tener en cuenta cuestiones sociales, rituales y económicas conjuntamente con la cuestión puramente física y la procedencia original de la base de la población ibérica.

La falta de datos sobre la época romana, y la medieval, especialmente la etapa islámica, hacen difícil relacionar los resultados obtenidos con los datos de las poblaciones actuales.

Indudablemente estamos iniciando una nueva metodología, que nos puede abrir nuevas perspectivas para el estudio del pueblo ibero, que no dudamos que serán de gran importancia cuando se tenga un muestreo suficiente.

Prof. Eduardo Arroyo Pardo
Eva Fernández Domínguez
Dpto de Toxicología y Legislación Sanitaria
Facultad de Medicina
Universidad Complutense de Madrid
28040 Madrid
earroyop@med.ucm.es
Arturo Oliver Foix
Museo de
Bellas de Castellón
Avda. Hermanos Bou, 28
12003 Castellón
aoliver@dipcas.es

\section{BIBLIOGRAFÍA}

ANDERSON S., BANKIER A.T., BARRELL B.G., BRUIJN M.H.L., COULSON A.R., DROUIN J., EPERON L.C., NIERLICH D.P., ROE B.A., SANGER F., SCHREIER P.H., SMITH A.J.H., STADEN R., YOUNG L.G., 1981: "Sequence and organization of the human mitochondrial genome". Nature, 290: 457-464.

ARTEAGA, O., PADRO, J., SANMARTÍ, E., 1990: El poblado ibérico del Tossal del Moro de Pinyeres (Batea, Terra Alta, Tarragona). Mongrafies Arqueológiques, 7. Barcelona.

AUILERA, I., ROYO, I., 1978: Poblados hallstátticos del valle del Huecha. Contribución al estudio de la I Edad del Hierro. Cuadernos de Estudios Borjanos, 2. Borja

BERMISHEVA MA, KUTUEV IA, KORSHUNOVA TI, DUBOVA NA, VILLEMS R, KHUSNUTDINOVA EK., 2004: "Phylogeografic analysis of mitochondrial ADN Nogays: the high level of mixture of maternal lineages from Eastern and Western Eurasia”. Mol Biol (Mosk). 38(4), 617-624.

BURILLO, F., 1980: El valle medio del Ebro en época ibérica. Contribución a su estudio en los ríos Huervas y Jiloca medio. Zaragoza.

BURILLO, F., 1989-1990: "La crisis del ibérico antiguo y su incidencia sobre los Campos de Urnas finales del Bajo Aragón". Kalathos, 9-10, 95-124.

BURILLO, F., 2001-2002: "Propuesta de una territorialidad étnica para el Bajo Aragón: los Ausetanos del Ebro u Ositanos". Kalathos, 20-21, 159-187. 
CÓRTE-REAL H., MACAULAY V.A., RICHARDS M.B. HARITI G., ISSAD M.S., CAMBON-THOMSEN A. PAPIHA S., BERTRANPETIT J., SYKES B.C., 1996: "Genetic diversity in the Iberian Peninsula determined from mitochondrial sequence analysis". Ann. Hum. Genet. 60 331-350.

DeGUSTA D., COOK C.H., SENSABAUGH G., 1994: "Dentin as a source of ancient DNA". Ancient ADN Newsletter. 2(1), 13.

FERNÁNDEZ E., 2005: Polimorfismos de ADN mitocondrial en poblaciones antiguas de la cuenca mediterránea. Tesis Doctoral, Universidad de Barcelona.

FERNÁNDEZ E., ARROYO E., 2004: Análisis de ADNmt en restos óseos de tres yacimientos de la provincia de Castellón. Informe técnico presentado en el Museo de Bellas Artes de Castellón.

GÓMEZ BELLARD, F., 1996: "El análisis antropológico de las cremaciones". Homenaje al profesor Manuel FernándezMiranda, II, 55-64.

IZAGIRRE N., DE LA RÚA C., 1999: "A mtDNA analysis in ancient Basque populations: implications for haplogroup $\mathrm{V}$ as a marker for a major Palaeolithic expansion from southwestern Europe". Am. J Hum. Genet. 65, 199-207.

KUROSAKI K., MATSUSHITA T., UEDA S., 1993: "Individual DNA identification from ancient human remains". Am J Hum Genet. 53(3), 638-643.

MIGUEL IBÁÑEZ, M.P. de, 2005: "Muertos y ritos. Aportes desde la osteoarqueología". Actas de las I Jornadas de Arqueología Ibérica. La Contestania Ibérica, treinta años después, 325-336.

OLIVER FOIX, A., 1995: "Acerca de los restos humanos localizados en los poblados ibéricos". Arx, 1, 35-41.

OLIVER FOIX, A., 2006: El Puig de la Nau, Benicarló. Castellón.

OOTA H., SAITOU N., MATSUSHITA T., UEDA S., 1995: "A genetic study of 2,000-year-old human remains from Japan using mitochondrial DNA sequences". Am. J Phys. Anthropol. 98, 133-145.

RICHARDS M., MACAULAY V., HICKEY E., VEGAE., SYKES B., GUIDA V., RENGO C., SELLITTO D., CRUCIANI F., KIVISILD T., VILLEMS R., THOMAS M., RYCHKOV S., RYCHKOV O., RYCHKOV Y., GOLGE M., DIMITROV D., HILL E., BRADLEY D., ROMANO V., CALI F., VONA G., DEMAINE A., PAPIHA S., TRIANTAPHYLLIDIS C., STEFANESCU G., HATINA J., BELLEDI M., DI RIENZO A., NOVELLETTO A., OPPENHEIM A., NORBY S., AL-ZAHERI N., SANTACHIARA-BENERECETTI S., SCOZARI R., TORRONI A., BANDELT H.J., 2000: "Tracing European founder lineages in the Near Eastern mtDNA pool". Am. J. Hum. Genet. 67(5), 1251-1276.

SAMPIETRO, M., CARAMELLI, D., LAO, O., CALAFELL, F., COMAS, D., LARI, M., AGUSTI, B., BERETRANPETIT, J., LALUEZA FOX, C., 2005: "The genetics of the Pre-Roman Iberian Peninsula: A mtDNA Study of Ancient Iberians". Annals of Human Genetics, 69, 535-548.

SANMARTÍ, J., SANTACANA, J., 2005: Els ibers del nord. Barcelona.

SULLIVAN K., MANNUCCI A., KIMPTON C., GILL P., 1993 "A rapid and quantitativc ADN sex test: fluorescence-based PCR analysis of $X-Y$ homologous gene amelogenin". BioTechniques. 15(4), 636-641.

TAMBETS K., ROOTSI S., KIVISILD T., HELP H., SERK P., LOOGVALI E.L., TOLK HV, REIDLA M, METSPALU E, PLISS L, BALANOVSKY O, PSHENICHNOV A BALANOVSKA E, GUBINA M, ZHADANOV S, OSIPOVA L, DAMBA L, VOEVODA M, KUTUEV I, BERMISHEVA $M$, KHUSNUTDINOVA E, GUSAR V, GRECHANINA E, PARIK J, PENNARUN E, RICHARD C, CHAVENTRE A
MOISAN JP, BARAC L, PERICIC M, RUDAN P, TERZIC R, MIKEREZI I, KRUMINA A, BAUMANIS $V$, KOZIEL $S$, RICKARDS O, DE STEFANO GF, ANAGNOU N, PAPPAKI, MICHALODIMITRAKIS E, FERAK V, FUREDI S, KOMEL R, BECKMAN L, VILLEMS R., 2004: "The western and eastern roots of the Saami-the story of genetic "outliers" told by mitochondrial DNA and $\mathrm{Y}$ chromosomes". Am J Hum Genet. 74(4), 661-682.

TORRONI A., BANDELT H.-J., D'URBANO L., LAHERMO P., MORAL P., SELLITO D., RENGO C., FORSTER P., SAVONTAUS M.-L., BONNÉ-TAMIR B., SCOZZARI R., 1998: "mtDNA analysis reveals a major late Palaeolithic population expansion from southwestern to northeastern Europe". Am. J. Hum. Genet. 62, 1137-1152.

TORRONI A., BANDELT H.J., MACAULAY V., RICHARDS M., CRUCIANI F., RENGO C., MARTINEZ-CABRERA V., VILLEMS R., KIVISILD T., METSPALU E., PARIK J., TOLK H.V., TAMBETS K., FORSTER P., KARGER B., FRANCALACCI P., RUDAN P., JANICIJEVIC B., RICKARDS O., SAVONTAUS M.L., HUOPONEN K., LAITINEN V., KOIVUMAKI S., SYKES B., HICKEY E., NOVELLETTO A., MORAL P., SELLITTO D., COPPA A., AL-ZAHERI N., SANTACHIARA-BENERECETTI A.S., SEMINO O., SCOZZARI R., 2001: «A signal, from human mtDNA, of postglacial recolonization in Europe". Am. J. Hum. Genet. 69(4), 844-852.

TRAMULLAS SAZ, J., ALFRANCA, L.M., 1995: "El valle medio del Ebro durante la Primera Edad del Hierro: las destrucciones y abandonos de poblados durante los siglos $\mathrm{VI}$ y $\mathrm{V}$ a.C. y su relación con el mundo ibérico y celtibérico". III Simposio sobre los Celtiberos. Poblamiento celtiberico. (Daroca, 1991), 275-280.

WOODWARD S.R., KING M.J., CHIU N.M., KUCHAR M.J., GRIGGS C.W., 1994: "Amplification of ancient nuclear DNA from teeth and soft tissues". PCR Meth and Appl. 3, 244-247

ZIERDT H., HUMMEL S., HERRMANN B., 1996: "Amplification of human short tandem repeats from medieval teeth and bone samples". Hum Biol. 68(2), 185-199.

\section{Bases de datos consultadas}

The Concordance of Nucleotide Substitutions in the Human mtDNA Control Region. University of Cambridge,

UK. World Wide Web: http://shelob.bioanth.cam.ac.uk/mtADN/.

MILLER K.W.P. DAWSON J.L., HAGELBERG E. 1996. A concordance of nucleotide substitutions in the first and second hypervariable segments of the human mtDNA control region. Int J Leg Med. 109: 107-113.

mtDB-Human Mitochondrial Genome Database.

http://www.genpat.uu.se/mtDB/.

INGMAN M. Molecular Anthropology. Section of Medical Genetics. Department of Genetics and Pathology. Uppsala University, Sweden.

mtDNA Population database (FBI).

http://www.fbi.gov/hq/lab/fsc/backissu/april2002/miller1. htm\#Introduction.

MONSON K.L., MILLER K.W.P., WILSON M.R.,DIZINNO J.A., BUDOWLE B. The mtDNA Population Database: An Integrated Software and Database Resource for Forensic Comparison. Forensic Science Communications 4(2).

Para más información sobre ADN antiguo y otras cuestiones, recomendamos consulten nuestra página web http://www. ucm.es/info/genforen/ 